\title{
ANÁLISE ERGONÔMICA E AMBIENTAL DE UMA EMPRESA METALÚRGICA DO RAMO DE AGROINDÚSTRIAS E DERIVADOS DE CANA DE AÇÚCAR
}

\author{
Dauto Pivetta Carpes ${ }^{l}$, Airton dos Santos Alonçol, Gessieli Possebom ${ }^{1}$, Antonio Robson Moreiral, Rafael Sobroza Beckerl, Bruno \\ Christiano Correa Ruiz Zart ${ }^{l}$, Tiago Gonçalves Lopes ${ }^{l}$
}

${ }^{1}$ Departamento de Engenharia Rural, Universidade Federal de Santa Maria, 97105-900, Santa Maria, Brasil.

*E-mail: dautocarpes@gmail.com

\section{RESUMO}

Dentre as linhas de atuação da análise ergonômica do trabalho, há a avaliação dos fatores de realização de uma determinada tarefa. As condições de trabalho podem influenciar diretamente no aumento de produtividade, lucros, redução de perdas, além de proporcionar conforto e segurança dos trabalhadores. Desse modo, este trabalho teve por objetivo avaliar as posturas realizadas durante uma jornada de trabalho, bem como as condições ambientais, elaborando diagnósticos e possíveis recomendações, em cinco setores de uma empresa metalúrgica no município de Jaguari - RS. Foi aplicado um questionário para verificação do funcionamento geral da empresa e observadas as condições de iluminação e ruído para realização das tarefas de cinco funcionários. A análise postural foi realizada através da observação no ambiente de trabalho e também através de imagens com o auxílio do software Ergolândia 5.0, com a utilização dos métodos RULA e OWAS. Através das análises, foi observado que apenas um posto de trabalho não estava conforme a norma para iluminância de interiores, e nenhum dos postos atendia à norma de referência para ruído. Ainda, a maioria dos funcionários realizavam algum tipo de esforço para o carregamento de peças, o que corrobora para os resultados dos métodos posturais que apresentaram necessidade de investigação e correções em alguns postos de trabalho. Assim, concluiu-se que existe a necessidade da adoção de mudanças em alguns postos de trabalho, principalmente no que se refere às condições posturais de realização das tarefas.

Palavras-chave: Análise postural do trabalho. RULA. OWAS.

\section{Introdução}

A busca pelo aumento de produtividade do trabalho está aliando o aumento de tecnologia em mecanismos de produção, com a adaptação dos meios necessários, de forma que proporcionem o bem-estar e segurança dos trabalhadores.

A redução dos custos de produção e a elevação dos índices de produção podem estar relacionados com a melhoria da segurança e saúde do trabalhador. De acordo com Quelhas e Lima [1], estas metas podem ser alcançadas com a redução das interrupções da jornada de trabalho relacionadas às condições inadequadas, absenteísmo, acidentes e doenças ocupacionais.

A avaliação dos fatores que podem ocasionar o surgimento de lesões por esforços repetitivos e distúrbios osteomusculares relacionados ao trabalho (LER/DORT) considera, segundo o Ministério da Saúde do Brasil [2], aspectos de trabalho como: força, repetitividade, posturas inadequadas, vibração e/ou compressão mecânica, pausas insuficientes durante a jornada de trabalho, movimentos forçados não habituais, e cargas musculares estáticas. O nível de risco atribuído a cada um destes fatores deve considerar a sua intensidade, duração e frequência [3].

Kaschuk e Lopes [4] realizaram um levantamento das principais causas de acidentes ocorridos em uma indústria de perfis de aço e concluíram que os acidentes de maior ocorrência compreendem cortes superficiais, esmagamento de dedos e corte de dedos em máquinas do tipo guilhotina.

De acordo com Santos e Fialho [5], a análise ergonômica do trabalho (AET) pode ser subdividida em três fases: análise da demanda, análise da tarefa e análise das atividades. Na análise da demanda é realizada a definição do problema a ser avaliado com os atores em questão, ao passo que na análise da tarefa são consideradas as condições técnicas, ambientais e organizacionais e na análise das atividades, há a visualização e avaliação do trabalho que é efetivamente executado pelo trabalhador, bem como o seu comportamento.

Desse modo, por meio da análise da atividade é possível mensurar as exigências atribuídas a cada trabalhador, com um estudo minucioso de cada posto de trabalho [6]. 
O objetivo geral dessa avaliação foi realizar a aplicação da análise ergonômica do trabalho, da análise da tarefa e da atividade, avaliando as posturas realizadas durante a jornada de trabalho e as condições ambientais proporcionadas aos funcionários em uma empresa metalúrgica e, a partir dos resultados obtidos, elaborar sugestões e recomendações para o aperfeiçoamento das condições de trabalho.

\section{Parte Experimental ou Metodologia}

A coleta de dados foi realizada no município de Jaguari, situado na região central do estado do Rio Grande do Sul, distante aproximadamente $431 \mathrm{~km}$ da capital Porto Alegre, em uma empresa metalúrgica que atua na produção de equipamentos para micro destilarias de álcool combustível, derivados da cana-de-açúcar e pequenas vinícolas.

Foi realizada a análise ergonômica do trabalho (AET) por meio de uma visitação e inspeção ao ambiente de produção da empresa, ao longo de uma jornada de trabalho, com a finalidade de verificar a postura empregada para execução das atividades, além das condições técnicas, ambientais e organizacionais.

A avaliação das condições de iluminação foi realizada com utilização de um luxímetro digital portátil e, a emissão de ruídos com o auxílio de um decibelímetro digital. Seguiu-se as recomendações das normas NBR 5413[7], referentes à iluminância de interiores e NR17 [8], referentes aos níveis de ruídos para conforto acústico.

A mensuração de iluminação ocorreu em situação real de trabalho, próximo ao local de realização da atividade. Para a avaliação de ruído, o decibelímetro, operando em circuito de compensação A, foi posicionado próximo ao ouvido esquerdo do operador, conforme recomendações da norma em referência. Ambas as mensurações foram realizadas em quatro repetições e, posteriormente, determinada a média.

A análise postural foi efetuada empregando os métodos OWAS e o RULA, através do software Ergolândia 5.0. O método RULA foi utilizado a partir da observação dos membros superiores (braços, antebraços e punhos) e inferiores (pescoço, tronco, pernas e pé), em situação de trabalho durante o tempo necessário para realização da tarefa. A postura avaliada estava baseada nas relações das angulações entre os membros e o corpo, de forma que fossem atribuídas pontuações, compreendidas entre: 0 pontos, que representa a postura com menor risco de lesão e 4 pontos, que representa a postura com maior risco de lesão para o segmento corporal avaliado, conforme descrição do método na Tabela 1.

A partir dessas informações, foi elaborada a pontuação para avaliação, através da visualização das posturas, em condição normal de trabalho e também pela análise de imagens feitas com uma câmera fotográfica digital, modelo SONY DSCW30. Para a interpretação dos resultados, foi utilizada a tabela de pontuação e determinação de intervenção, Tabela 2.

Tabela 2. Pontuação geral para determinação do nível de intervenção ergonômica método RULA.

\begin{tabular}{|c|c|c|}
\hline Nível & Pontuação & Nível de intervenção \\
\hline 1 & 1 ou 2 & $\begin{array}{l}\text { Postura aceitável, desde que não mantida por } \\
\text { longos períodos }\end{array}$ \\
\hline 2 & 3 ou 4 & $\begin{array}{l}\text { Investigar postura, alterações poderão ser } \\
\text { necessárias }\end{array}$ \\
\hline 3 & 5 ou 6 & Investigar postura, introduzir alterações \\
\hline 4 & 7 & Investigar postura, alterar de forma urgente \\
\hline
\end{tabular}

Fonte: Adaptado de McAtmney [9].

O método OWAS foi aplicado por meio da realização da análise e da observação de posturas, as quais foram classificadas de acordo com as posições efetuadas para realização de uma determinada atividade. $\mathrm{O}$ método apresenta uma escala de quatro dígitos, sendo que o primeiro, o segundo, o terceiro e o quarto algarismo indicam, respectivamente, as posições das costas, braços, pernas e a esforço empenhado, conforme descrição da Tabela 3.

Tabela 3. Descrição dos fatores de avaliação do método OWAS

\begin{tabular}{|c|c|c|}
\hline $\begin{array}{c}\text { Membr } \\
\text { o } \\
\text { avaliad } \\
\text { o } \\
\end{array}$ & $\begin{array}{l}\text { Pontuaçã } \\
\text { o }\end{array}$ & Postura Observada \\
\hline \multirow{4}{*}{ Costas } & 1 & Ereta \\
\hline & 2 & Inclinada \\
\hline & 3 & Ereta e Torcida \\
\hline & 4 & Inclinada e Torcida \\
\hline \multirow{3}{*}{ Braços } & 1 & Braços abaixo do nível do ombro \\
\hline & 2 & Um braço no nível ou acima dos ombros \\
\hline & 3 & Braços no nível ou acima dos ombros \\
\hline \multirow{7}{*}{ Pernas } & 1 & Sentado \\
\hline & 2 & Em pé, ambas as pernas esticadas \\
\hline & 3 & Em pé, com o peso de uma das pernas esticada \\
\hline & 4 & $\begin{array}{l}\text { Em pé ou agachado, apresentando flexão de ambos } \\
\text { os joelhos }\end{array}$ \\
\hline & 5 & Em pé ou agachado, com um dos joelhos dobrado \\
\hline & 6 & Agachado em um ou ambos os joelhos \\
\hline & 7 & Andando ou em movimentação \\
\hline \multirow{3}{*}{ Esforço } & 1 & Carga menor ou igual a $10 \mathrm{~kg}$ \\
\hline & 2 & Carga maior que $10 \mathrm{~kg}$ e menor ou igual a $20 \mathrm{~kg}$ \\
\hline & 3 & Carga maior que $20 \mathrm{~kg}$ \\
\hline
\end{tabular}

Fonte: Adaptado de Ergolândia 5.0 (2014).

Baseada nas avaliações e verificações das posturas, através da visualização no ambiente de trabalho e por meio de fotografias, foi elaborada uma determinação de classes, e avaliada conforme a Tabela 4 . 
Tabela 4. Descrição das classes e níveis de ação do método OWAS.

\begin{tabular}{ccl}
\hline Classes & Pontuação & \multicolumn{1}{c}{ Nível de intervenção } \\
\hline 1 & $1-2$ & $\begin{array}{l}\text { Postura normal, dispensa cuidados } \\
\text { Postura que deve ser verificada rotineiramente nos } \\
\text { métodos de trabalho }\end{array}$ \\
3 & $5-6$ & $\begin{array}{l}\text { Postura merece atenção a curto prazo } \\
4\end{array}$ \\
27 & Postura merece atenção imediata
\end{tabular}

Fonte: Adaptado de Ergolândia 5.0 (2014).

Ainda, foi realizada uma vistoria inicial nos postos de trabalho da empresa, o que possibilitou a constatação de que alguns dos funcionários desempenhavam funções que eram comuns aos outros (o corte, a montagem e a solda de componentes), evidenciando que não havia um posto de trabalho fixo para os mesmos. Desse modo, foram selecionados cinco trabalhadores que desenvolviam atividades em local determinado, cujas funções desempenhadas podem ser observadas no Quadro 1.

Foi aplicado aos funcionários selecionados um questionário (Quadro 2) com o objetivo de obter conhecimento da organização e das condições durante a jornada de trabalho para elaboração dos produtos, sendo que as respostas objetivas ( $\operatorname{sim} /$ não) possibilitaram, também, a coleta de observações descritas pelos mesmos.

Tabela 1. Descrição dos fatores de avaliação do método RULA

\begin{tabular}{|c|c|c|}
\hline Membro em exposição & Pontuação & Avaliação da Posição \\
\hline \multirow{4}{*}{ Pescoço } & 1 & Flexão entre $0^{\circ}$ e $10^{\circ}$ \\
\hline & 2 & Flexão entre $10^{\circ}$ e $20^{\circ}$ \\
\hline & 3 & Flexão maior que $20^{\circ}$ \\
\hline & 4 & Se existir extensão \\
\hline \multirow{4}{*}{ Tronco } & 1 & Sentado, com ângulo de quadril-tronco de $90^{\circ}$ ou mais \\
\hline & 2 & Flexão entre $0^{\circ}$ e $20^{\circ}$ \\
\hline & 3 & Flexão entre $20^{\circ} \mathrm{e} 60^{\circ}$ \\
\hline & 4 & Flexão maior que $60^{\circ}$ \\
\hline \multirow{4}{*}{ Braço } & 1 & $20^{\circ}$ de extensão até $20^{\circ}$ de flexão \\
\hline & 2 & Extensão maior que $20^{\circ}$ ou flexão entre $20^{\circ}$ e $45^{\circ}$ \\
\hline & 3 & Flexão entre $45^{\circ}$ e $90^{\circ}$ \\
\hline & 4 & Flexão maior que $90^{\circ}$ \\
\hline \multirow{2}{*}{ Antebraço } & 1 & Flexão entre $60^{\circ}$ e $100^{\circ}$ \\
\hline & 2 & Flexão menor que $60^{\circ}$ ou maior que $100^{\circ}$ \\
\hline \multirow{3}{*}{ Punho } & 1 & Posição neutra \\
\hline & 2 & Flexão ou extensão entre $0^{\circ}$ e $15^{\circ}$ \\
\hline & 3 & Flexão ou extensão maior que $15^{\circ}$ \\
\hline \multirow{3}{*}{ Rotação do pulso } & 1 & Rotação Média \\
\hline & 2 & Rotação Externa \\
\hline & 3 & Flexão entre $0^{\circ}$ e $10^{\circ}$ \\
\hline \multirow{2}{*}{ Pernas } & 1 & Pernas e Pés apoiados e com equilíbrio \\
\hline & 2 & Pernas e Pés sem apoio e equilíbrio apropriados \\
\hline \multirow{4}{*}{ Fator Força/Carga } & 0 & Carga menor que $2 \mathrm{~kg}$ (Intermitente) \\
\hline & 1 & Carga entre 2 e $10 \mathrm{~kg}$ (Intermitente) \\
\hline & 2 & Carga entre 2 e 10 kg (Repetitiva ou estática) \\
\hline & 3 & Carga maior que $10 \mathrm{~kg}$ (Repetitivo ou choque) \\
\hline
\end{tabular}

Fonte: Adaptado de McAtamney [9].

\begin{tabular}{|c|c|c|}
\hline $\begin{array}{c}\text { Funcionár } \\
\text { io }\end{array}$ & $\begin{array}{l}\text { Função desempenhada no } \\
\text { posto de trabalho }\end{array}$ & Posições de trabalho \\
\hline $\mathrm{F} 1$ & Torneiro mecânico & Em pé \\
\hline $\mathrm{F} 2$ & Soldador & Em pé/sentado \\
\hline F3 & $\begin{array}{l}\text { Cortador de chapas de alumínio, } \\
\text { polimento e acabamento }\end{array}$ & $\begin{array}{l}\text { Em pé/ agachado/ } \\
\text { curvado }\end{array}$ \\
\hline $\mathrm{F} 4$ & $\begin{array}{l}\text { Moldagem, corte e montagem } \\
\text { de itens em polipropileno }\end{array}$ & Em pé \\
\hline F5 & $\begin{array}{l}\text { Setor de alambique, moldagem, } \\
\text { montagem }\end{array}$ & $\begin{array}{l}\text { Em pé/ sentado/ } \\
\text { curvado }\end{array}$ \\
\hline
\end{tabular}

\section{Resultados e discussões}

A etapa inicial deste estudo engloba a realização da análise da tarefa, em que foram coletadas informações para a compreensão da organização do trabalho, as quais estão descritas na Tabela 5.

A empresa trabalha no modo de produção Just in time, ou seja, a produção é realizada de acordo com a demanda dos clientes. Assim, inicialmente o produto é vendido, para que depois possa ser comprada a matéria-prima necessária e, posteriormente, ocorra a fabricação ou montagem. O estoque de matéria prima dentro da empresa é reduzido, porém suficiente para elaboração de pequenos projetos. 
Tabela 5. Diagnóstico da organização do trabalho.

\begin{tabular}{|c|c|}
\hline Fator & Descrição/ Execução \\
\hline Sistema de produção & Just in Time \\
\hline Turno de trabalho & Matutino/Vespertino \\
\hline Jornada de trahalho & (Segunda à Sexta) \\
\hline Jomada ue travaino & Manhã: 7:30 h / 11:45 h - Tarde: 13:30 h / 18:00 h \\
\hline Ritmo de trabalho & Contínuo \\
\hline Horas extras & Eventualmente \\
\hline Contratação de pessoal & $\begin{array}{c}\text { Currículo, Experiência, Conhecimentos básicos, } \\
\text { Atividades regionais }\end{array}$ \\
\hline Divulgação da empresa & $\begin{array}{c}\text { Internet, Feiras, Parcerias com entidades como } \\
\text { EMATER, EMBRAPA }\end{array}$ \\
\hline Prazos & Dependente da complexidade do projeto \\
\hline Assistência Técnica & Arquiteta \\
\hline
\end{tabular}

Assim, depois de realizado o projeto do produto com as especificações do cliente, ocorre a verificação do estoque de materiais disponíveis pelo coordenador de produção e, quando necessária, a compra do material faltante através de uma tomada de preços. Os prazos de entrega dos produtos dependem da abrangência do projeto, pois alguns podem ter curta duração, de 45 a 60 dias, e outros, de maior complexidade, podem ter duração de 6 a 24 meses.

O turno de trabalho contempla a manhã e tarde, em ritmo contínuo, não ocorrendo substituição de funcionários. Durante a jornada de trabalho são realizadas algumas paradas somente quando necessário, não havendo intervalos de descanso.

A contratação de funcionários ocorre conforme a necessidade da empresa e a seleção compreende a consideração de fatores como currículo, experiência, conhecimentos básicos e conhecimentos sobre as atividades e cultura local.

Excluindo-se o funcionário responsável pelo serviço de torno e fresa, segundo os mesmos, grande parte dos funcionários não possui atividade especificada em contrato de trabalho, desempenhando funções, conforme as necessidades para elaboração de um determinado produto.

\subsection{Avaliações dos fatores ambientais}

$\mathrm{Na}$ Tabela 6, estão expostos os valores percentuais de conformidade, quando comparados aos valores de iluminação pontual coletada/ iluminação média recomendada, conforme a NBR 5413 [7]. Também são apresentados os dados obtidos em relação ao nível de ruído, visto que todos os trabalhadores faziam o uso contínuo de protetor auricular.
Observa-se que apenas o posto de trabalho do F1 não está conforme a recomendação da norma de iluminância de interiores, apresentando, aproximadamente, $17,50 \%$ de atendimento à norma, que também orienta sobre o fato de que a iluminação em qualquer ponto do campo de trabalho não seja inferior a $70 \%$ da iluminância média recomendada. Assim, considerando que o posto citado, anteriormente, exige um alto grau de precisão na realização das atividades, é provável que sejam sugeridas alterações para adequação da luminosidade. Dul e Weerdmeester [10] afirmam que o olho humano demora mais tempo para se adaptar quando existem grandes diferenciais de brilho luminoso.

Os outros postos atendem integralmente à recomendação da norma. Esse fator pode estar relacionado com a associação da iluminação artificial com a natural, através da utilização de telhas translúcidas na cobertura da edificação. Fatores como cansaço visual, ocorrência de erros, acidentes e diminuição da produtividade, de acordo com IIda [11], podem estar relacionados aos níveis de iluminação incorretos.

Com relação aos ruídos,conforme a recomendação da NR17 [8], o nível de ruído aceitável para efeitos de conforto no ambiente é de até $65(\mathrm{~dB})$. Observa-se que nenhum dos 5 postos de trabalho, quando em atividade, atendem à orientação da norma. $\mathrm{O}$ posto de trabalho do $\mathrm{F} 3$ apresenta maior intensidade devido à utilização de ferramentas de corte e desgaste de componentes metálicos.

Considerando-se que o ritmo de trabalho é de alta intensidade e que os funcionários estão expostos à emissão de ruídos em intervalos frequentes de tempo, de acordo com a NR15 [12], quando há a utilização de proteção auricular, tal atividade pode ser classificada como não insalubre. Dessa forma, para que seja assegurada a saúde auditiva do trabalhador, de acordo com Braga [13], 140 dB é o valor máximo que o tímpano pode suportar sob risco de rompimento, pois a partir de $90 \mathrm{~dB}$ começam a ocorrer danos ao organismo humano.

\subsection{Questionário de avaliação das condições de realização das tarefas}

O questionário foi aplicado com o objetivo de obter informações gerais sobre as condições disponíveis para a realização das tarefas. Foram entrevistados cinco funcionários, com as questões apresentadas no Quadro 2, os quais responderam perguntas de forma objetiva e com observações, quando julgadas necessárias: 
Quadro 2. Questionário de condições de realização das tarefas.

\begin{tabular}{|l|c|c|}
\hline \multicolumn{1}{|c|}{ Pergunta realizada } & \multicolumn{2}{|c|}{ Resposta } \\
\cline { 2 - 3 } & Sim & Não \\
\hline $\begin{array}{l}\text { Realiza esforço com as mãos, braços ou coluna, } \\
\text { aplicando força extrema ou realizando movimentos } \\
\text { bruscos ou com uso de marreta? }\end{array}$ & $60 \%$ & $40 \%$ \\
\hline $\begin{array}{l}\text { Realiza carregamento de peso superior a 25 kg } \\
\text { indivualmente? }\end{array}$ & $60 \%$ & $40 \%$ \\
\hline $\begin{array}{l}\text { É necessária a realização de desvio postural, de forma } \\
\text { extrema ou muito errada para algum segmento } \\
\text { corporal? }\end{array}$ & $80 \%$ & $20 \%$ \\
\hline $\begin{array}{l}\text { Tronco predominantemente encurvado durante a } \\
\text { jornada de trabalho? }\end{array}$ & $60 \%$ & $40 \%$ \\
\hline $\begin{array}{l}\text { Durante a realização das atividades, é possível realizar } \\
\text { alguma sentado de forma confortável? }\end{array}$ & $40 \%$ & $60 \%$ \\
\hline $\begin{array}{l}\text { Durante a jornada de trabalho existe alto nível de } \\
\text { ruído, calor, vibração ou outro fator, que torne a } \\
\text { atividade desconfortável? }\end{array}$ & $80 \%$ & $20 \%$ \\
\hline Já houve envolvimento em acidentes de trabalho? & $60 \%$ & $40 \%$ \\
\hline $\begin{array}{l}\text { Exigência de exames períodicos de saúde e ou vacina } \\
\text { anti-tetânica }\end{array}$ & $100 \%$ & $0 \%$ \\
\hline
\end{tabular}

A maioria dos funcionários realiza algum tipo de esforço ou carregamento de peso para desempenhar a sua atividade, visto que quase a totalidade dos componentes utilizados são constituídos de ferro ou alumínio, tendo uma variação de peso de 25 a $100 \mathrm{~kg}$.

A manipulação e montagem destes componentes requer, na maioria das vezes, um esforço manual, com exceção das condições extremas em que é utilizado um guincho hidráulico. Conforme Matheus [14] essas características apresentam um grande risco ergonômico, devido aos movimentos repetitivos e também ao peso dos equipamentos que, na maioria das vezes, são transportados de maneira incorreta.

Quanto aos desvios posturais, quase a totalidade dos entrevistados relataram que precisam fazer posições para atender a um determinado tipo de moldagem, montagem, solda ou carregamento, em função do tamanho variado de estruturas que são fabricadas pela empresa, de forma que haja um desconforto, principalmente no pescoço e nas costas. Abrantes [15] afirma que a altura adequada e o correto posicionamento dos postos de trabalho podem contribuir para que não exista a necessidade de o trabalhador deixar a sua posição de equilíbrio.

Tabela 6. Comparação dos dados coletados de Iluminância com a NBR 5413 e níveis de ruídos com a NR17 nos postos de trabalho.

\begin{tabular}{|c|c|c|c|c|c|c|c|}
\hline Funcionário & Tarefa & $\begin{array}{c}\text { Iluminação } \\
\text { coletada } \\
\text { (Lux) }\end{array}$ & $\begin{array}{l}\text { Recomendação } \\
\text { NBR } 5413 \text { (Lux) }\end{array}$ & Situação & $\begin{array}{l}\text { Nível de Ruído } \\
\text { coletado (dB) }\end{array}$ & $\begin{array}{l}\text { Recomendação } \\
\text { NR17 (dB) }\end{array}$ & Situação \\
\hline $\mathrm{F} 1$ & Torneiro mecânico & 175 & 1000 & Não atende & 91,5 & 65 & Não atende \\
\hline $\mathrm{F} 2$ & Soldador & 550 & 200 & Atende & 77,8 & 65 & Não atende \\
\hline F3 & $\begin{array}{l}\text { Cortador de chapas de alumínio, } \\
\text { polimento e acabamento }\end{array}$ & 630 & 500 & Atende & 93,4 & 65 & Não atende \\
\hline $\mathrm{F} 4$ & $\begin{array}{l}\text { Moldagem, corte e montagem } \\
\text { de itens em polipropileno }\end{array}$ & 625 & 500 & Atende & 85,4 & 65 & Não atende \\
\hline F5 & $\begin{array}{l}\text { Setor de alambique, moldagem, } \\
\text { montagem }\end{array}$ & 860 & 500 & Atende & 84,1 & 65 & Não atende \\
\hline
\end{tabular}

Conforme os funcionários, as atividades raramente podem ser executadas na posição sentada, exceto no posto de soldas e moldagem de chapas para alambiques, dependendo do tamanho dos componentes. Afirmam, ainda, que o alto ritmo de atividades praticamente impossibilita pausas ou que permaneçam sentados, mesmo que por pequenos períodos. Com relação ao fator citado anteriormente, Brasil [17] comenta que a postura mais adequada ao trabalhador é aquela que possa ser escolhida livremente e alterada ao longo do tempo.

Outros fatores relatados envolvem: o nível de ruído, que é constante durante a jornada de trabalho, devido à utilização de ferramentas para efetuar polimento, corte e moldagem de peças metálicas e a temperatura que, principalmente no verão, causa desconforto pela obrigatoriedade de utilização dos EPI's. Tendo em vista este último fator, cabe ressaltar que a empresa não possui exaustores ou sistema de ventilação, mas somente portões laterais que são abertos, dependendo das condições climáticas, o que também ocasiona a concentração de gases/fumaça nos postos de trabalho de solda metálica, além dos componentes de polipropileno, fazendo com que, na maioria das vezes, ocorra a inalação desses gases pelo funcionário. De acordo com Fuhr [18] a função exercida pelo soldador é uma das atividades que mais apresentam doenças ocupacionais, devido à exposição do trabalhador a uma maior incidência de agentes químicos, físicos e biológicos.

Três funcionários, ou seja, $60 \%$ dos entrevistados, já se envolveram em acidentes de trabalho. Conforme relatos dos mesmos, as causas principais compreendem a queda de objetos que podem ocasionar cortes em determinadas partes do corpo, como os braços e as pernas. Outros casos que foram relatados e estão relacionados com a perfuração de dedos por broca furadeira e a projeção de limalha de ferro nos olhos, fato que ocorre devido ao descuido do funcionário e a ausência de utilização de óculos protetores. 
Com relação ao acompanhamento da saúde do trabalhador, a empresa, semestralmente, recebe uma equipe de médicos ocupacionais que realizam avaliações e recomendações, quando necessárias. Todos os funcionários relataram que os exames e vacinas foram exigidos no momento da contratação, o que está de acordo com as recomendações da NR 7 [19].

Considerando os fatores de risco inerentes às atividades, é importante ressaltar os estudos de Bansi [20]. O autor comenta que a saúde ocupacional pode auxiliar na prevenção de acidentes, bem como proporcionar uma melhor adequação dos funcionários às suas atividades. Além disso, evita implicações legais por falta de atendimento à sua obrigatoriedade e garante a manutenção da saúde dos empregados.

\subsection{Análise postural dos funcionários}

A avaliação das posturas foi realizada utilizando-se os métodos RULA e OWAS, observando-se as posturas durante a jornada de trabalho e coletando fotografias que possibilitassem a visualização e posterior análise para aplicação dos métodos. $\mathrm{Na}$ tabela 7, são expostos os resultados das análises obtidos pelo método de análise postural RULA, com a pontuação final e o nível de ação necessário, utilizando o software Ergolândia 5.0.

Alguns funcionários realizam suas tarefas de maneira distinta, ou seja, algumas etapas são realizadas na posição sentada e outras em pé, como no caso dos funcionários F2 e F5. Esta variação ocorre devido ao tamanho do componente em trabalho e também pelo tipo de equipamento necessário para desempenhar a atividade sendo, portanto, realizadas duas verificações para contemplar todo o processo. A alternância de posições pode ser benéfica, de acordo com Hall [21], em função da variação na posição corporal, o que altera a pressão discal interna, favorecendo a movimentação de nutrientes que removem o desgaste metabólico.

Já para o funcionário $\mathrm{F}$ 3, foi realizada a análise com a execução da tarefa de corte e moldagem e outra para ajustes e montagem, sendo que as duas são realizadas na posição em pé. De acordo com IIda [11], a posição em pé proporciona uma maior mobilidade corporal.

Após as análises posturais, foram observadas três condições de realização das tarefas no nível 2, três no nível 3 e duas no nível 4. Esses níveis classificam as mudanças de acordo com a urgência necessária para evitar o surgimento de DORT.

Conforme os dados da tabela 7 é possível verificar que a função dois apresenta a necessidade de mudanças imediatas quando o trabalhador desempenha a atividade na posição sentada. Assim, possivelmente deverão ocorrer alterações na altura da bancada de trabalho ou no assento, de modo que o funcionário não necessite realizar posições que prejudiquem a coluna e o pescoço durante a atividade, uma vez que esses dois segmentos corpóreos foram relatados pelo trabalhador como locais de maior desconforto.

Tabela 7. Análise das tarefas com a metodologia RULA.

\begin{tabular}{|c|c|c|c|}
\hline Função & Pontuação & Nível* & Ação recomendada \\
\hline $\mathrm{F} 1$ & 3 & $2 \mathrm{EP}$ & $\begin{array}{l}\text { Deve-se realizar uma observação. } \\
\text { Podem ser necessárias mudanças }\end{array}$ \\
\hline \multirow{2}{*}{$\mathrm{F} 2$} & 3 & $2 \mathrm{EP}$ & $\begin{array}{l}\text { Deve-se realizar uma observação. } \\
\text { Podem ser necessárias mudanças }\end{array}$ \\
\hline & 7 & $4 \mathrm{~S}$ & $\begin{array}{l}\text { Devem ser introduzidas mudanças } \\
\text { imediatamente }\end{array}$ \\
\hline \multirow{2}{*}{$\mathrm{F} 3$} & 4 & $2 \mathrm{CM}$ & $\begin{array}{l}\text { Deve-se realizar uma observação. } \\
\text { Podem ser necessárias mudanças }\end{array}$ \\
\hline & 7 & $4 \mathrm{AM}$ & $\begin{array}{l}\text { Devem ser introduzidas mudanças } \\
\text { imediatamente }\end{array}$ \\
\hline $\mathrm{F} 4$ & 6 & $3 \mathrm{EP}$ & $\begin{array}{l}\text { Deve-se realizar uma investigação. } \\
\text { Devem ser introduzidas mudanças }\end{array}$ \\
\hline \multirow{2}{*}{ F5 } & 6 & $3 \mathrm{EP}$ & $\begin{array}{l}\text { Deve-se realizar uma investigação. } \\
\text { Devem ser introduzidas mudanças }\end{array}$ \\
\hline & 5 & $3 \mathrm{~S}$ & $\begin{array}{l}\text { Deve-se realizar uma investigação. } \\
\text { Devem ser introduzidas mudanças }\end{array}$ \\
\hline
\end{tabular}

Para a função três, a atividade de ajustes e montagem requer uma alteração imediata, de modo que, na condição observada, o funcionário apresentava flexão excessiva da coluna por períodos intermitentes. A realização do trabalho em bancadas possibilitaria a execução das atividades com a coluna ereta, diminuindo o ângulo de flexão e extensão do tronco e braço (ombro), proporcionando maior conforto ao funcionário e reduzindo a exposição do mesmo a transtornos nos membros superiores.

Sobre as funções classificadas no nível três, deverão ser aplicadas investigações de uma forma mais detalhada, visto que apresentaram necessidades de mudanças, mesmo que de forma não urgente.

A tabela 8 apresenta os dados da análise da tarefa realizadas com o método OWAS, e apresenta a sequência de dígitos utilizados para classificar a postura observada e também a classe de urgência da intervenção.

A tarefa desempenhada pelo funcionário 1 não apresenta necessidade de mudanças corretivas, visto que ambos os braços podem ser mantidos no nível ou abaixo dos ombros, as pernas permanecem estendidas e as costas predominantemente mantidas na posição ereta. As cargas movimentadas para inserção de componentes no local de usinagem não excedem $10 \mathrm{~kg}$ e, quando em níveis superiores, são efetuadas com auxílio de guincho hidráulico. Também não foram identificadas medidas corretivas

TECNO-LÓGICA, Santa Cruz do Sul, v. 23, n. 1, p. 28-35, jan./jul. 2019 
para as tarefas do F3 na posição EP/CM, F4 e F5 para ambas as posições.

A tarefa realizada por $\mathrm{F} 2$ apresenta necessidade de mudanças em um futuro próximo, devido à posição do tronco ser flexionada para o alcance nos diversos pontos do material a ser processado, quando a atividade é realizada em pé. Quando sentado, a postura realizada faz com que o funcionário flexione o pescoço e o tronco para maior visualização do ponto de solda.

Tabela 8. Análise das tarefas com a metodologia OWAS

\begin{tabular}{|c|c|c|c|c|}
\hline Função & $\begin{array}{c}\text { Postura } \\
\text { Observada }\end{array}$ & $\begin{array}{c}\text { Class } \\
\text { e }\end{array}$ & Posição* & Ação recomendada \\
\hline $\mathrm{F} 1$ & $1-1-2-1$ & 1 & EP & $\begin{array}{l}\text { Não são necessárias } \\
\text { mudanças corretivas }\end{array}$ \\
\hline \multirow{2}{*}{$\mathrm{F} 2$} & $2-1-1-1$ & 2 & S & \multirow{2}{*}{$\begin{array}{l}\text { São necessárias mudanças em } \\
\text { um futuro próximo } \\
\text { São necessárias mudanças em } \\
\text { um futuro próximo }\end{array}$} \\
\hline & $2-1-2-1$ & 2 & $\mathrm{EP}$ & \\
\hline \multirow{2}{*}{ F3 } & $2-1-3-3$ & 3 & $\mathrm{EP} / \mathrm{AM}$ & \multirow{2}{*}{$\begin{array}{l}\text { São necessárias correções tão } \\
\text { logo quanto possível } \\
\text { Não são necessárias } \\
\text { mudanças corretivas }\end{array}$} \\
\hline & $1-1-2-3$ & 1 & $\mathrm{EP} / \mathrm{CM}$ & \\
\hline $\mathrm{F} 4$ & $1-2-2-2$ & 1 & EP & $\begin{array}{l}\text { Não são necessárias } \\
\text { mudanças corretivas }\end{array}$ \\
\hline \multirow{2}{*}{ F5 } & $1-1-2-2$ & 1 & $\mathrm{EP}$ & $\begin{array}{l}\text { Não são necessárias } \\
\text { mudanças corretivas }\end{array}$ \\
\hline & $1-1-2-2$ & 1 & S & $\begin{array}{l}\text { Não são necessárias } \\
\text { mudanças corretivas }\end{array}$ \\
\hline
\end{tabular}

* EP - Em pé; $\mathrm{S}$ - Sentado; CM - Corte e moldagem; AM - Ajuste e montagem

Na posição EP/AM do F3 foram recomendadas adequações em um curto espaço de tempo, pois a realização da atividade é feita de maneira que a coluna permaneça com flexão acentuada por períodos intermitentes e com a utilização de ferramentas e componentes que variam de 10 a $20 \mathrm{~kg}$. A execução das atividades adotando-se bancada para deposição dos componentes seria um provável fator para solucionar os desvios posturais.

\section{Conclusões}

A análise ergonômica do trabalho possibilitou a verificação de situações que podem contribuir para a ocorrência de desconforto durante a jornada de trabalho e também o surgimento de possíveis DORT.

$\mathrm{O}$ posto de trabalho do funcionário $\mathrm{F} 3$ apresenta a maior necessidade de adequações, devido às posturas avaliadas apresentarem condição de risco para o aparecimento de DORT.

\section{ERGONOMICS AND ENVIRONMENTAL ANALYSIS OF A METALLURGICAL COMPANY IN THE FIELD OF AGROINDUSTRY AND SUGARCANE DERIVATIVES}

ABSTRACT: Within the lines of actuation of the ergonomic analysis of work, there is the evaluation of the factors involved in the accomplishment of a certain task. Work conditions may directly influence on the increase of productivity and profits, on the reduction of losses, besides providing comfort and safety for workers. This way, the objective of this study was to evaluate the employees' posture during a working day, as well as the environmental conditions, elaborating diagnostics and possible recommendations, in five sectors of a metallurgical company in the municipality of Jaguari - RS. A questionnaire was applied to verify the general functioning of the company and the lighting and noise conditions were observed for the work tasks of five employees. The posture analysis was performed through observation in the work environment and through images, with the aid of Ergolândia 5.0 software, by using the methods RULA and OWAS. Through the analyzes, it was observed that only one workstation did not conform to the standard for interior lighting, and none of the stations met the noise reference standard. Moreover, most of the employees performed some type of effort when carrying the parts, which corroborated the results of the posture methods that showed the need for investigation and corrections in some workstations. Thus, it was concluded that there is the need for the adoption of changes in some workstations, especially regarding the posture conditions for the accomplishment of the tasks.

Keywords: Postural analysis of work. RULA. OWAS

\section{Referências}

[1] QUELHAS, O. L. G.; LIMA, G. B. A. Sistema de gestão de segurança e saúde ocupacional: fator crítico de sucesso à implantação dos princípios do desenvolvimento sustentável nas organizações brasileiras. Interfacehs, Vol. 1, n. 2, p. $1-34,2006$.

[2] MINISTÉRIO DA SAÚDE DO BRASIL. Protocolo de investigação, diagnóstico, tratamento e prevenção de lesões por esforços repetitivos: distúrbios osteomusculares relacionados ao trabalho. Brasília: Ministério da Saúde. 2000.

[3] SANTOS, H. H. Abordagem clínica e psicossocial das Lesões por Esforços Repetitivos LER / DORT. Revista brasileira de saúde ocupacional, Vol. 28, p. 105$106,2003$.

[4] KASCHUK, O.; LOPES, V., J., S. Riscos de Acidentes de Trabalho na Operação de Máquinas de Corte e Dobra de Aço em uma Indústria no Município de Sinop/MT. 2013. Disponível em: <http://www.abepro.org.br/biblioteca/TN_STO_241_399_33786.pdf.>. Acesso em: 4 jun. 2018.

[5] SANTOS, N.; FIALHO, F. Manual de análise ergonômica do trabalho. Curitiba: Genesis. Vol. 2, 1997. 
[6] ALEXANDRE R. N. da C.; MENDONÇA, R. S; SILVA S. C; MONTEIRO, L. F; SANTOS, M. B. G. Aplicação da análise ergonômica do trabalho em uma indústria do setor moveleiro. In: Encontro Nacional De Engenharia De Produção, 31. 2011, Belo Horizonte. Disponível em:

〈http://www.abepro.org.br/biblioteca/enegep2011_tn_sto_138_875_17910.pdf〉. Acesso em 09 de maio de 2018.

[7] NBR 5413 - NORMA REGULAMENTADORA N ${ }^{\circ}$ 5413. Iluminância de interiores. ABNT - Associação Brasileira de Normas Técnicas, 1992. 13p.

[8] NR17 - NORMA REGULAMENTADORA N 17 . Ergonomia. Ministério do Trabalho e Emprego. 14p. 2007. Disponível em:

<http://www.mte.gov.br/legislacao/.> Acesso em: 11 maio 2018.

[9] McATAMNEY, L.; CORLETT, E.N. RULA: A survey method for the investigation of work-related upper limb disorders. Applied Ergonomics, Vol. 24, n. 2, p. 91- 99, 1993.

[10] DUL, J. WEERDMEESTER, B. Ergonomia Prática. São Paulo: Edgar Blucher, 2004

[11] IIDA, I. Ergonomia: projeto e produção. 2.ed. São Paulo: Edgard Blucher, 2005.

[12] NR15 - Norma Regulamentadora $\mathrm{N}^{\circ} 15$. Atividades e Operações insalubres. Ministério do Trabalho e Emprego. 1990. Disponível em: <http://www.mte.gov.br/legislacao/>. Acesso em 11 maio de 2018.

[13] BRAGA, B. HESPANHOL, I. CONEJO, J. G. L. MIERZWA, J. C. BARROS, M.T. L. SPENCER, M. PORTO, M. NUCCI, N. JULIANO, N. EIGER, S. Introdução à Engenharia Ambiental. 2. Ed. São Paulo: Prentice Hall, 2005.

[14] MATHEUS, B.P. Risco químico relacionado aos fumos de solda e poeira metálica. Revista rede de cuidados em saúde, Vol. 3, n. 3, p. 1-10, 2009.

[15] ABRANTES, Antônio Francisco. Atualidades em ergonomia- Logística, Movimentação de materiais, Engenharia Industrial, Escritórios. São Paulo: IMAM, 2004.

[17] BRASIL, Ministério do Trabalho e Emprego. Secretaria de Inspeção do Trabalho. Departamento de Segurança e Saúde no Trabalho. Nota Técnica 060/2001. Assunto: NR 17 Ergonomia - indicação de posturas a ser adotada na concepção de postos de trabalho. Brasília, 2001.

[18]FUHR, T. A. Reconhecimento e avaliação dos riscos ambientais gerados nos processos de soldagem de uma empresa do segmento metal mecânico. Monografia. Ijuí: Unijuí; 2012. Disponível em:

<http://bibliodigital.unijui.edu.br:8080/xmlui/bitstream/handle/123456789/1259/ Monografia\%20Tiago\%20A.\%20F\%C3\%BChr\%20\%20Vers\%C3\%A3o\%20Fina 1.pdf?sequence=1>. Acesso em: 11 junho de 2018 .

[19]NR 7 - NORMA REGULAMENTADORA 7. Programa de controle médico de saúde ocupacional. 1998. Disponível em:

<http://www.guiatrabalhista.com.br/legislacao/nr/nr7.htm.>. Acesso em 12 de maio de 2018

[20] BANSI, A. C.; MARTOS, S. R.; STEFANO, S. R. Acidentes no trabalho e programas de prevenção em uma empresa de construção civil. Revista de Ciências Jurídicas e Empresariais, Vol. 13, p. 95-102, 2015.

[21]HALL, S. J. Biomecânica Básica. Tradução: Giuseppe Taranto. $4^{a}$ ed. Rio de Janeiro: Editora Guanabara Koogan, 2005. 